\title{
FOTO
}

\section{Superficies fotográficas: el resto, el trazo y las imágenes en crisis}

\section{Photographic surfaces: the rest, the trace and the images in crisis}

\author{
Natalia Fortuny \\ Universidad de Buenos Aires / Conicet - Argentina \\ https://orcid.org/0000-0002-7239-6951 \\ nataliafortuny@gmail.com
}

\section{Resumen:}

Este artículo toma, por un lado, como punto de inflexión la crisis argentina de 2001 para enhebrar ciertas obras de la fotografía artística argentina que cruzan arte y política, evocando una de las experiencias de aquel estallido políticosocial. Por otro, piensa a la fotografía en su carácter objetual a partir de una importante dimensión de la materialidad fotográfica, posiblemente la más cercana a la imagen: su superficie. Puntualmente, se desplegarán las estrategias visuales de dos conjuntos fotográficos: la serie Bancos, de Juan Travnik (20032005) y Corralito, de Nuna Mangiante (2009). La imagen fotográfica, superficie ella misma, captura en estas series la propia superficie de los espacios de la ciudad en crisis, en especial alrededor de sus consecuencias económicas y lo que se conoció como "el corralito bancario". Sus procedimientos y elecciones las definirán como memorias fotográficas de un pasado en crisis.

\begin{abstract}
:
This article takes, on the one hand, as a turning point the Argentine crisis of 2001 to thread certain works of Argentine artistic photography that intersect art and politics, evoking one of the experiences of that political-social outbreak. On the other hand, the article thinks of photography in its objectual nature from an important dimension of photographic materiality: its surface. Specifically, the visual strategies of two photographic groups will be displayed: the series Banks, by Juan Travnik (2003-2005) and Corralito, by Nuna Mangiante (2009). The photographic image, a surface itself, captures in these series the very surface of the spaces of the city in crisis, especially around its economic consequences and what was known as "the bank corralito". Their procedures and choices will define them as photographic memories of a past in crisis.
\end{abstract}

Palabras clave:

fotografía argentina; crisis de 2001; memoria colectiva; superficie; pasado reciente.

\section{Keywords:}

Argentine Photography; 2001 Crisis; Collective memory; Surface; Recent past. 
cuánta más dulcedumbre a lo largo, más honda superficie:

\section{Introducción}

César Vallejo

Desde que Nicéphore Niepce tomó en 1926 aquella primera imagen -una vista a través de su ventana- la ciudad ha sido uno de los grandes temas de la fotografía. Y desde los sucesos de la comuna de París, en 1871, la fotografía ha retratado y registrado con ahínco cada crisis desplegada en los trazados urbanos. Así, hemos visto ciudades desapaciguadas e incendiadas, en las que transita la represión y la violencia cubre sus calles. Y donde las avenidas tomadas se vuelven el lugar del en común y el espacio público de la revuelta.

En Argentina, la década del gobierno de corte neoliberal de Carlos Menem (1989-1999) desembocó en una época de grave crisis económica, política y social. Los sucesos de mayor tensión y revuelta popular ocurrieron los días 19 y 20 de diciembre de 2001, en los que fueron asesinadas 39 personas en distintas ciudades argentinas. Estos hechos provocaron la renuncia del entonces Presidente Fernando De La Rúa e inauguraron un período de inestabilidad política e institucional: en menos de dos semanas se sucederían cinco personas diferentes al frente de la Presidencia del país.

Las jornadas del 19 y 20 de diciembre fueron retratadas por la valiente cámara de los fotorreporteros, quienes arriesgaron sus cuerpos para documentar las protestas, la represión y los asesinatos. Sus fotos conforman la narración inmediata y visual de la crisis en nuestras memorias y marcan a su vez un suelo para cualquier posterior imagen fotográfica que se construya sobre estos acontecimientos. Entre las visiones paradigmáticas del centro de la ciudad de Buenos Aires que nos legaron durante esos últimos días de 2001 se encuentran: el obelisco rodeado por las llamas, los caballos de la infantería sobre los cuerpos de los manifestantes, los torsos desnudos al sol abrasante del verano, los lugares emblemáticos -tanto por su dimensión política como simbólica- como la Plaza de Mayo y el Congreso Nacional convertidos en arenas de la batalla y rodeados de espeso humo negro.

Estas imágenes del estallido perviven aún frescas en la memoria colectiva. Sin embargo, es posible también encontrar otras imágenes -posteriores, más 
silenciosas- que se abocan también a esos tiempos en crisis. Me refiero a artefactos estéticos que, años después, echarán mano de unos determinados recursos visuales para desplegar singulares dimensiones de los espacios urbanos atravesados por el malestar social y convertirse así en memorias visuales de ese pasado en crisis. ${ }^{1}$

Trabajaré aquí principalmente dos conjuntos fotográficos. La serie Bancos, de Juan Travnik (2003-2005) y Corralito, de Nuna Mangiante (2009). ${ }^{2}$ La imagen fotográfica, superficie ella misma, captura en estas series la propia superficie de la ciudad en crisis. Y en este vaivén, estas obras se constituyen como un suelo de intercambio entre fotografía, política e historia reciente. Sus procedimientos y elecciones las definirán como memorias fotográficas de un pasado aún muy cercano. En tanto memorias fotográficas condensan tres peculiaridades indisociables: su calidad de memorias sociales de un pasado en común -en un juego entre vivencias individuales y la historia-, su formato visual fotográfico -con todas las potencialidades temporales, estéticas y políticas de este lenguaje- y su elaboración artística -la creación y puesta en marcha de recursos visuales singulares en cada obra-.3

\section{Superficies fotográficas}

Son conocidos los trabajos que, además de pensar a la fotografía como imagen, intentan subrayar su carácter material y objetual. Tanto Geoffrey

\footnotetext{
1. Luego de la crisis de 2001 se abrió un período fructífero para pensar las relaciones entre arte y política. Para la relación entre arte y crisis de 2001 véase también los trabajos de Ana Longoni (2004, 2007, 2009), Andrea Giunta (2009) y Cecilia Vázquez (2011), entre otros. Una exposición que reunió obras de diferentes disciplinas artísticas, en especial instalaciones y arte activista, en referencia a la crisis argentina del 2001 fue la muestra $E x$ Argentina. La normalidad, que se expuso durante 2006 en el Palais de Glace. Reunía a más de 45 artistas de Argentina, Rusia, Chile, Brasil, Alemania, Holanda, Francia y Austria.

2. También obras fotográficas como las de Gabriel Valansi y Hugo Aveta han desplegado ciertas poéticas visuales alrededor de la crisis de 2001 (trabajé sobre estas series en Fortuny, 2018 y 2017 , respectivamente).

3. He trabajado el concepto de memorias fotográficas para pensar ciertas evocaciones visuales de posdictadura respecto de la violencia política y las desapariciones durante el último gobierno militar en Argentina (Fortuny, 2014) Así como existe un vasto conjunto de memorias fotográficas de la última dictadura, también pueden encontrarse en la fotografía argentina evocaciones a otros momentos traumáticos o críticos del pasado reciente, como es el caso de la crisis económica, política y social iniciada en 2001.
} 
Batchen como Elizabeth Edwards, por ejemplo, focalizan en el objeto fotográfico, en la cualidad de cosa de toda fotografía.

Batchen (2004) cree que es la singular combinación entre las dimensiones háptica y visual, entre tacto y vista, lo que convierte a la fotografía en un medio tan atractivo. Lo fundamenta, por ejemplo, en el caso de la fotografía pintada de los siglos XIX y XX, que llama nuestra atención sobre la superficie de la imagen y nos invita a imaginar el toque del pincel que animaba esa superficie. $\mathrm{O}$ en las fotos de los deudos sosteniendo el retrato del ausente, en las que pareciera que "los sujetos quisieran llamar nuestra atención no sólo hacia la imagen que sostienen, sino también a la fotografía misma como una entidad tangible, a la solidez reconfortante de su función de memoria”. (Batchen, 2004, p. 14) 4

Describir el carácter material de la fotografía implica pensarla no sólo como una imagen sino como una cosa tridimensional. Toda foto es, a la vez, imagen y objeto físico, ya que tiene volumen, opacidad, tactilidad y es una presencia física en el mundo, además de estar inmersa en interacciones subjetivas y corporales. Sin embargo, esta cualidad objetual de la foto parece no ubicarse en primer plano cuando se la mira, debido a la aparente transparencia del medio, que suprime nuestra consciencia de lo que la fotografía 'es' en términos materiales. (Batchen, 2004; Edwards y Hart, 2004)

Aquí nos ocuparemos de una dimensión particular de esta materialidad fotográfica, posiblemente la más cercana a la imagen: su superficie.

$\mathrm{Al}$ trabajar la relación entre imágenes e historia, Georges Didi-Huberman se pregunta por aquellas superficies que fueron testigos y sobrevivientes de atrocidades -por ejemplo, el piso del campo de concentración y exterminio nazi de Auschwitz Birkenau- y las considera "cortezas de la historia”.

Hay superficies que transforman el fondo de las cosas a su alrededor. Los filósofos de la idea pura, los místicos del Sanctasanctórum, solo piensan en la superficie como un maquillaje, una mentira: lo que esconde la verdadera

4. "It is as if, in these pictures within pictures, the subjects want to draw our attention not only to the image they hold, but also to photography itself as a touchable entity, to the comforting solidity of its memorial function." (Batchen, 2004, p. 14) [Traducción propia]. 
esencia de las cosas. (...) Se puede pensar, al contrario, que la sustancia decretada más allá de las superficies es sólo un señuelo metafísico. (...) La corteza no es menos verdadera que el tronco. Me atrevo a decir que es incluso a través la corteza cómo se expresa el árbol. En todo caso se presenta a nosotros. 'Aparece' de 'aparición' y no simplemente de 'apariencia'. La corteza (...) está en alguna parte de la conexión entre una apariencia fugitiva y una inscripción sobreviviente. (Didi-Huberman, 2014, p. 66)

Retomaremos aquí esa idea de imagen como superficie y corteza, como algo que ha estado y que es la capa visible de algo vivido. Ya que serán las superficies fotográficas de ciertas obras -las tensiones que estas obras ponen en juego en esas superficies- lo que nos permita pensar la historia reciente en crisis.

Por otro lado, ¿cuál es la superficie de lo urbano? Gran parte de esta superficie lo constituyen las fachadas de sus edificios. La fachada (del latín facies y del italiano facciata, "cara exterior") es lo visible: un límite del interior que se derrama como exterior hacia lo público. La fachada entabla un diálogo con los otros: presenta un estilo -habla de sí- y propone una relación con la ciudad y con sus habitantes.

En particular, los edificios que alojan a las instituciones bancarias se han destacado históricamente en el horizonte de las ciudades por sus frentes y fachadas. Así, las construcciones de los bancos conforman un caso específico del paisaje de la ciudad de Buenos Aires. El Diccionario de arquitectura en la Argentina establece que desde mediados de siglo XIX la arquitectura bancaria constituye un renglón importante dentro la actividad arquitectónica. Aunque a lo largo de las décadas se sucedieron diferentes estilos y planteos tipológicos, en general las construcciones bancarias tradicionales se han destacado en el emplazamiento urbano por sus fachadas macizas. Una de las principales tipologías de los bancos, por ejemplo, cumple el propósito de destacar de su entorno a las sucursales bancarias a partir de un gran salón con importante altura. De esta manera, durante las décadas del treinta y del cuarenta, y especialmente en la ciudad de Buenos Aires, se 
generalizaron las fachadas 'tipo telón' de gran monumentalidad. (Liernur y Aliata, 2004, p. 121)

Será precisamente un elemento sensible de las fachadas bancarias agregado ad hoc a fines de 2001 -y paradigmático de la poscrisis argentina- aquello que se pondrá en cuestión en las series trabajadas a continuación. Se trata de obras que tensionan a la vez la superficie fotográfica para así retratar las superficies urbanas atravesadas por la crisis y el corralito bancario.

¿A qué se conoció, entonces, en Argentina, como 'corralito'?

Uno de los hechos que desembocaron en el estallido de las jornadas de $19 \mathrm{y}$ 20 de diciembre de 2001 fue la firma del decreto 1570/2001 por parte de Domingo Cavallo, entonces Ministro de Economía. Esta medida económica conocida como 'corralito' fue aplicada el 3 de diciembre de 2001 en medio del creciente desempleo y el profundo empobrecimiento de grandes sectores de la población. Luego de 10 años de paridad cambiaria y de mantener la moneda nacional al mismo valor que el dólar, el fin de la convertibilidad se acompañó del 'corralito' para limitar la extracción de dinero en efectivo de las cuentas bancarias. Destinada a retener el dinero en el sistema financiero en el contexto del nuevo tipo de cambio, la medida afectó principalmente a los pequeños ahorristas. El "corralito" fue una

(...) restricción impuesta desde el poder ejecutivo al retiro en efectivo de los depósitos de los bancos. Según esta normativa, los ahorristas sólo podrían retirar un máximo de 250 pesos o 250 dólares por semana de sus cuentas, dejando acorralado el resto de sus depósitos bancarios. Por lo cual, ya nadie podría usar libremente sus propios fondos: por ley los bancos retendrían el grueso del dinero, asegurándose así un límite en la salida de dinero en efectivo del sistema. Si en septiembre el Gobierno había aprobado la ley de Intangibilidad de los depósitos (ley 25.466) para asegurar su protección, con la llegada del corralito había asegurado el arrebato total. (Zicari, 2014, p. 58)

Los investigadores Iñigo Carrera y Cotarelo argumentan que el corralito afectó no solamente a las capas medias y fue además uno de los detonantes principales de la insurrección espontánea de los días 19 y 20 de diciembre: 
Cuando a fines de noviembre se produjo el crac bancario, el gobierno limitó el retiro de dinero de los bancos: impuso el llamado corralito. Este no sólo incluía los ingresos, atesoramientos e inversiones de pequeños propietarios, sino también los salarios: la bancarización decretada anteriormente forzaba a realizar todas las transacciones económicas a través de los bancos. A la vez, los asalariados públicos recibían sus sueldos con atraso y parcialmente pagados en bonos provinciales, lo mismo que los desocupados sus subsidios; muchos asalariados privados recibían sus salarios en pequeñísimas cuotas. Se produjo una situación semejante a la que se había dado en mayo y junio de 1989 con la hiperinflación: la desaparición del dinero como medio de cambio. Las protestas de diciembre fueron, en lo inmediato, la respuesta al corralito, que recibió un repudio generalizado, no sólo de los "ahorristas de clase media", como plantea una mirada autocentrada en la pequeña burguesía, sino también de organizaciones sindicales como la CTA y ambas CGT. (Iñigo Carrera y Cotarelo, 2006, p. 53) 5 .

Al verse despojados de sus ahorros en dólares (pesificados, devaluados y confiscados), los damnificados continuaron durante 2002 con las protestas, los cacerolazos y las manifestaciones delante de los bancos. ${ }^{6}$ En respuesta a estas manifestaciones y a los destrozos provocados durante los sucesos de diciembre en los frentes vidriados de las entidades bancarias -en especial las situadas en el microcentro de la ciudad de Buenos Aires- éstas colocaron rápidamente, por delante de sus fachadas, una segunda fachada más resistente hecha de materiales como hierro y chapas. Una suerte de superficie o vestimenta que, a partir de la crisis, cubrió a los bancos de la ciudad por largos años, reemplazando el propio perfil de cada compañía y

5. Para los autores "el rechazo al llamado corralito excede a la clase media en tanto son afectados por esa medida los asalariados insertos en la llamada economía formal y las capas más pobres del proletariado insertas en el trabajo en negro. La meta de todas estas fracciones y capas no se limita exclusivamente a sus reivindicaciones económicas inmediatas sino que está presente el rechazo a lo que es percibido como un abuso de autoridad (manifestado tanto en la acción de la policía como en la declaración del estado de sitio) por parte de un gobierno que se tornó ilegítimo a los ojos del pueblo en la medida en que constituyó, en todos los aspectos, una continuidad degradada del gobierno anterior." (Iñigo Carrera y Cotarelo, 2006, p. 89)

6. A modo de ejemplo véase simplemente algunas notas de los principales diarios durante los primeros meses de 2002: La Nación http://edant.clarin.com/diario/2002/05/04/e00702.htm, Clarín http://www.lanacion.com.ar/372324-protesta-de-ahorristas-en-la-city , y Página/12 https://www.pagina12.com.ar/diario/elpais/subnotas/2944-1528-2002-0316.html 
cada frente por estos parapetos que, aunque diferentes, igualaban a todos los bancos y los señalaban claramente en el entramado urbano con un único sentido: Esto es un banco.

\section{La superficie como resto}

Juan Travnik es un fotógrafo argentino nacido en Buenos Aires que desarrolla su obra personal desde 1970. Su influencia en el panorama de la fotografía argentina de las últimas décadas no se ciñe solamente a su labor como fotógrafo sino también a su amplia tarea como docente y curador. Desde 1998 hasta 2015 ha dirigido la FotoGalería del Teatro San Martín y en 2001 creó y condujo el Espacio Fotográfico del Teatro de la Ribera, ambos en Buenos Aires. Dirige la Licenciatura de Fotografía en la Universidad Nacional de San Martín y ha participado en numerosas muestras nacionales e internacionales. Es también ensayista y Miembro de Número de la Academia Nacional de Bellas Artes.

En su serie Bancos, Travnik ofrece unas posibles superficies fotográficas de la crisis, retratando en primer plano estas construcciones de chapa y metal que las entidades bancarias colocaron delante de sus puertas para resguardarlas y evitar el ingreso masivo de los manifestantes que exigían la devolución de sus ahorros. Estas fotos de Travnik fueron hechas entre 2003 y 2005, es decir algunos años después del estallido de 2001, y entre otras cosas comprueban la perduración en el tiempo de las chapas colocadas delante de las puertas de los bancos.

Las fotos de esta serie de Travnik podrían describirse como abstracciones documentales: la toma es directa, la foto documental y sin embargo de gran carga pictórica. Fotografías pictóricas, ya que no pictorialistas. Cada una de ellas ofrece y privilegia un juego de luces, colores y formas. Precisamente, estas fotos marcan la llegada de Travnik al uso del color, siendo hasta entonces un fotógrafo que se ceñía estrictamente al blanco y negro. De todas maneras, en medio de este juego de formas cualquier espectador conocedor de la historia reciente de nuestro país comienza prontamente a advertir (a 
leer) las marcas de las protestas de los ahorristas sobre las puertas tapiadas de los bancos, las huellas de los golpes de los damnificados por el Estado y el sector financiero. Así, en lugar de pinceladas estas pinturas fotográficas sobre las chapas están conformadas, por un lado, por grafitis convenientemente borrados y vueltos a escribir y nuevamente borrados por las empresas, y, por otro, por las cinceladas de los martillazos de la protesta, que hendían la chapa con cada golpe, marcándola.

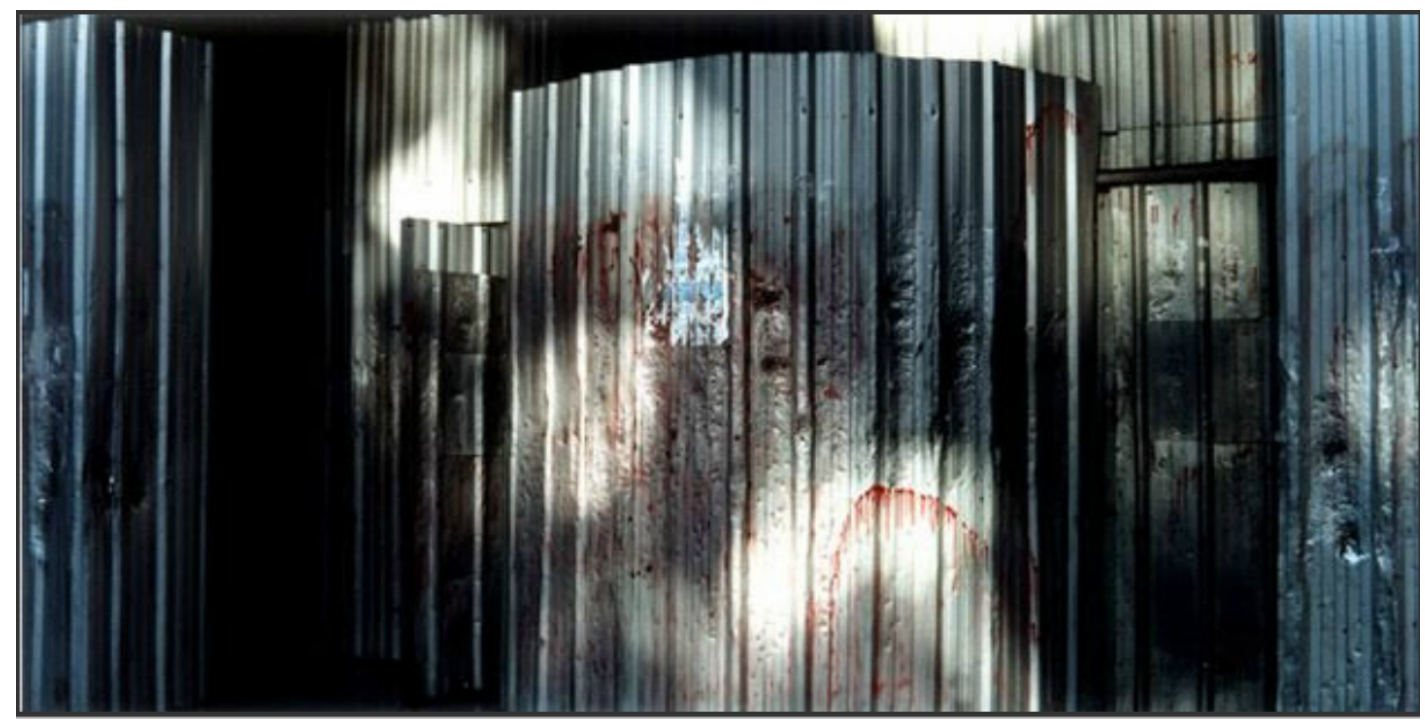

F1. Juan Travnik, Lloyds Bank, Buenos Aires, 2003.

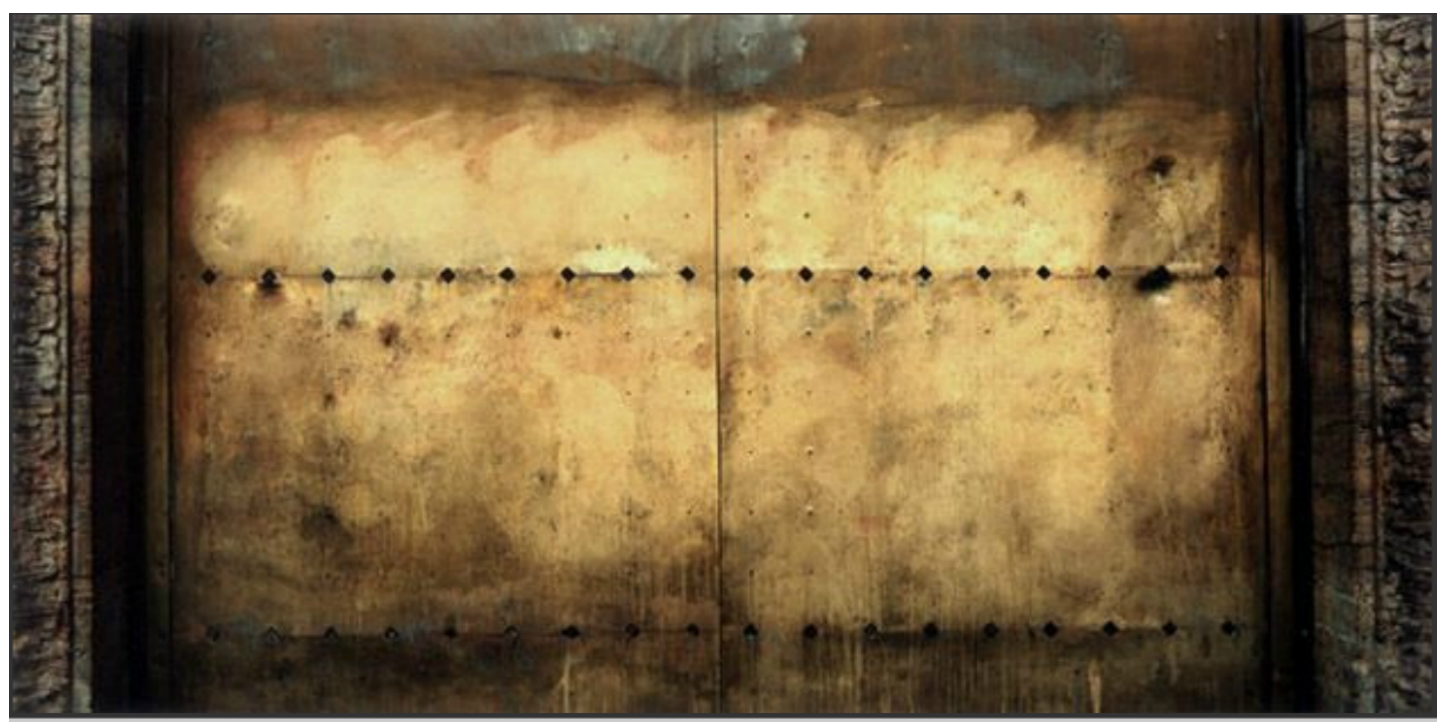

F2. Juan Travnik, HSBC, Buenos Aires, 2005. 


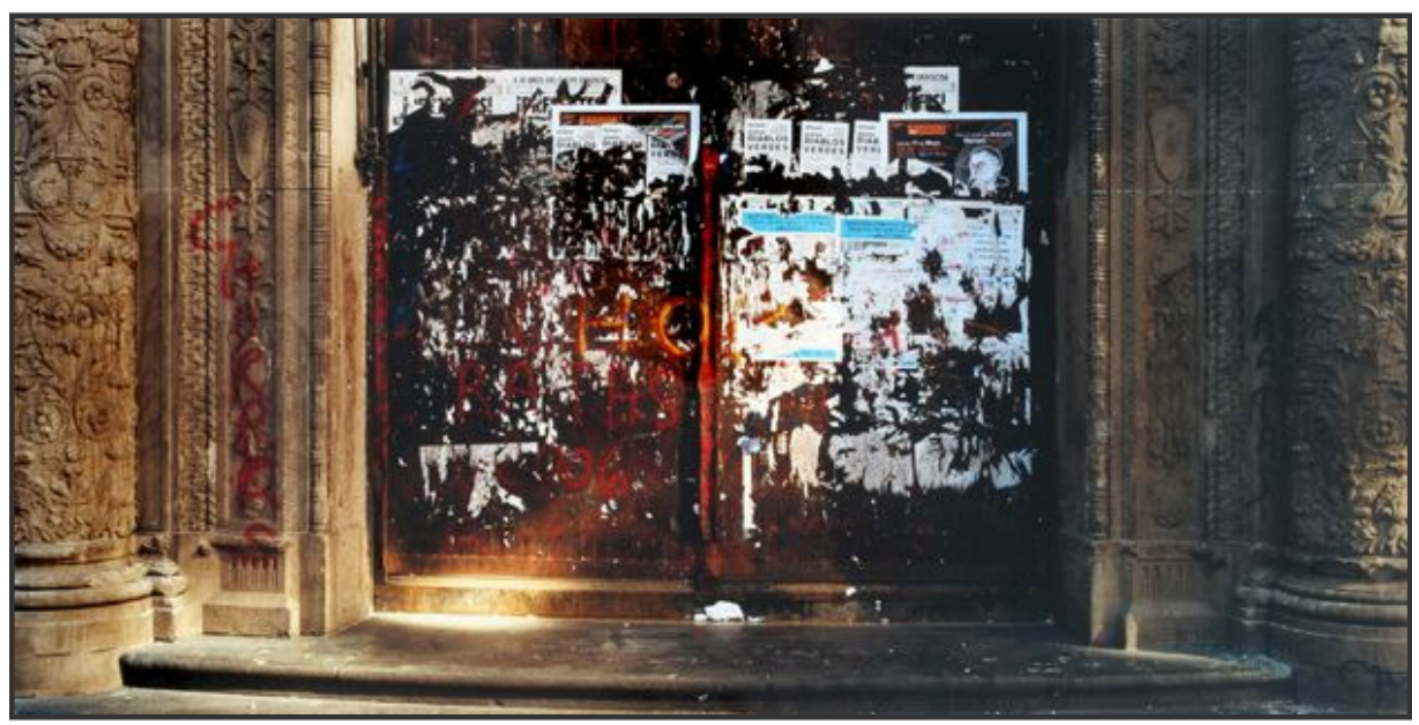

F3. Juan Travnik, Boston Bank, Buenos Aires, 2005.

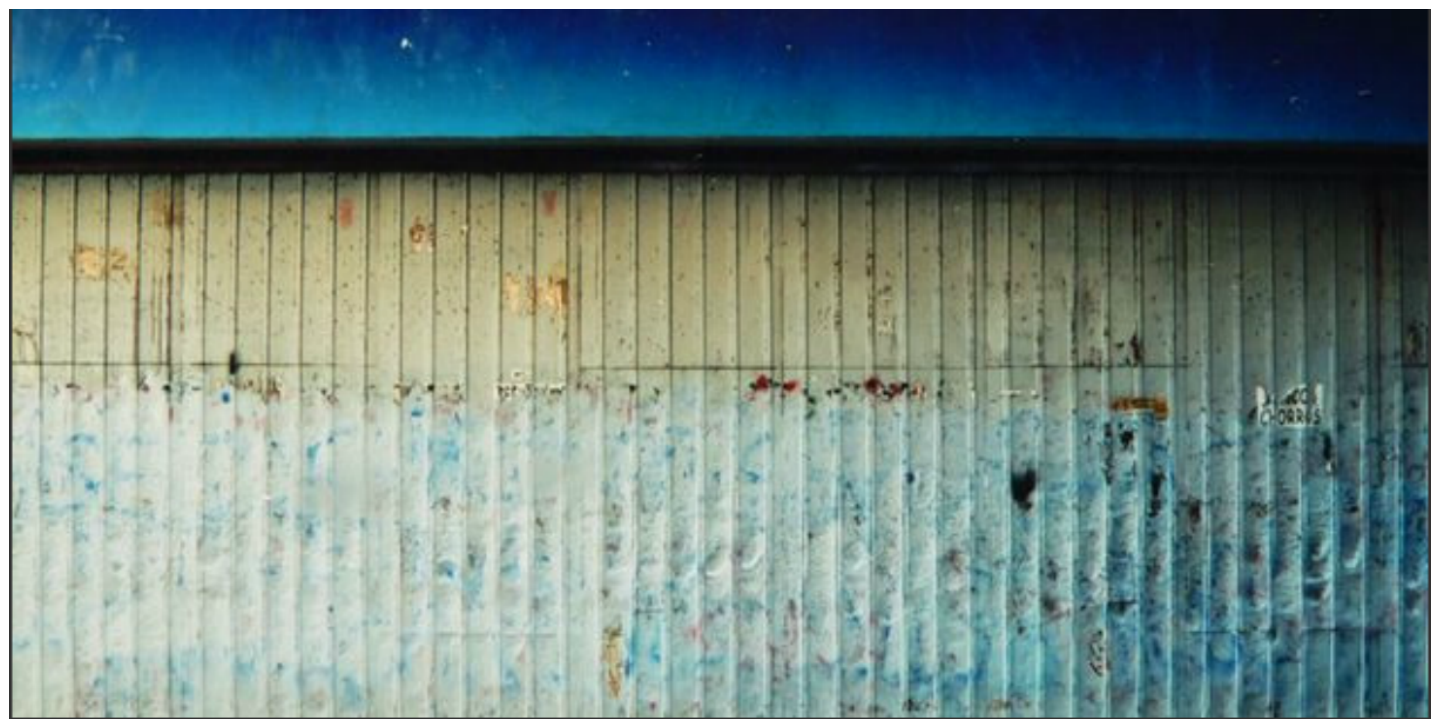

F4. Juan Travnik, Citi Bank, Buenos Aires, 2005.

En estas fotos Travnik trabaja una vez más con el paisaje urbano característico de su obra, ofreciendo vistas urbanas preciosas, a color, contando la crisis sin contar los cuerpos heridos ni la sangre de los muertos, ni las manifestaciones violentamente reprimidas, el deambular de los cartoneros o las numerosas fábricas cerradas. 7 Sino esta otra dimensión urbana cuasi permanente que ha expresado la singularidad del centro de la

7. Con enormes carros, familias enteras salían a la calle de noche -aún hoy salen, aunque en menor proporción- a disputarse la basura, en especial el cartón y papel, para clasificarla y llevarla a las zonas de venta por peso. Según una nota estigmatizante del Diario Clarín -en que habla de "los ejércitos de la noche"- en 2002 había 40 mil cartoneros en Buenos Aires. Véase http://edant.clarin.com/suplementos/zona/2002/10/27/z-00215.htm 
ciudad por largos años: los bancos con sus puertas tapiadas. Vilém Flusser (2015, p. 63) cree que la visión 'profunda' revela banalidad y que "es la visión superficial la que es osada". En línea con esto, hay una profunda tensión en estas imágenes de la superficie de las chapas puestas e intervenidas: ya sea pintadas, ya sea golpeadas. Lucen como cuadros abstractos y sin embargo se descubren de pronto huellas muy concretas. El laconismo del título de cada imagen -que menciona simplemente el nombre de la entidad bancariacolabora para advertir, luego de una primera mirada, ya un mapa donde leer las marcas de los golpes de la protesta. En sintonía con una búsqueda insistente en la obra de Travnik; aquí descrita con sus palabras:

Siento que siempre termino fotografiando a la gente a través de sus huellas. Una intervención en la pared, un cartel, un rayado de algo, cosas que aparecen casi tácitamente en el paisaje urbano. Entonces, ese paisaje se transforma en algo misterioso que encierra un escenario y una acción a la vez, escenario y drama a la vez. Me interesa que aparezca ese clima. En ese deambular, me fascina la ciudad despoblada. Le encuentro un espíritu propio a los rincones cuando están vacíos. (en Etchelecu, 2016)

Estas huellas, como los restos, son incompletas por sí mismas, son indicios que ponen en relación dos tiempos, como pequeñas marcas materiales de una memoria borrosa que habrá que descrifrar y deshilvanar. Según Soulages (2008), toda estética de la imagen debe hacer frente a una serie de aparentes antinomias, propias de la propia pluralidad de la imagen. ${ }^{8}$

\footnotetext{
8. "Es necesario reunir en la misma estética, a la vez: la imagen de Lascaux y la imagen digital, la imagen de lo real y la imagen de lo virtual, la imagen fruto de la representación y la imagen fruto de la simulación, la imagen objeto y la imagen matriz, la imagen cosa y la imagen número, la imagen calco y la imagen calculada, la imagen traza y la imagen trazada, la imagen única y la imagen de imágenes, la imagen una y la imagen múltiple, la imagen aislada y la imagen multimedia, la imagen muda y la imagen sonora, la imagen fija y la imagen movimiento, la imagen temporal y la imagen fuera del tiempo, la imagen irreversible y la imagen inacabable, la imagen dada de una vez para siempre y la imagen transformada sin cesar por el observador,la imagen de la existencia y la imagen del lenguaje, la imagen visual y la imagen psíquica, la imagen matemática y la imagen ideológica, la imagen material y la imagen poética, la imagen sin-arte y la imagen artística, etc. (...) Estas antinomias son, entonces, una ocasión y una chance para quien quiera trabajar sobre una estética de la imagen." (Soulages, 2008, p. 97) Y también: "Es necesario entonces pensar esas tensiones y esos tironeos entre el referente y la foto, entre el objeto a fotografiar y el material, entre el acontecimiento pasado y las formas: ellos constituyen el valor y la unicidad de la fotografía. Ponen en relación con otras relaciones y tensiones que nutren la fotografía: lo irreversible y lo inacabable, el pasado y el presente, el "esto ha sido" y el "esto ha sido jugado", la traza y lo
} 
En efecto, la fotograficidad se articula con el "a la vez". Así, la estética del "a la vez" se funda sobre la esencia misma de la fotografía: toda foto es foto de alguna cosa. (...) Se debe privilegiar el "de", es decir pensar las relaciones que existen entre esa "alguna cosa" y el material fotográfico, entre lo real y la foto, $\mathrm{y}$, entonces, comprender las contradicciones y las tensiones que las componen, las oponen y las reúnen, en fin, se debe llevar a cabo para la fotografía, una reflexión dialéctica y una estética del "a la vez" - a la vez el infotografiable objeto a fotografiar y el material fotográfico- y rechazar por un lado, la ingenuidad realística, por el otro la reducción formalista o materialista. (Soulages, 2008, p. 102)

La estética del "a la vez" resuena entonces en estas fotos que trabajan la tensión de lo vivido y la forma. Si, retomando las intenciones esbozadas por Travnik, se interesa por que sus fotografías hablen "de escenario y drama a la $v e z "$, en estas imágenes el escenario se despliega en la sutileza de una superficie urbana puesta como defensa del capital financiero internacional y luego horadada por el martillo de la protesta continua. El drama, claro está, es aquello que la huella simplemente señala, el fuera de campo: los muertos en la represión durante el estallido de diciembre, las pérdidas de los ahorros bancarios, la desocupación, la miseria.

Las abstracciones documentales de estas fotos nos muestran la corteza de la historia, la traen hacia nuestra mirada. Y sin embargo la traen de manera transformada -transformación propia también del trabajo de la memoria-, en una poética del desplazamiento. Jacques Rancière (2011, p. 32) cree que la fotografía se ha convertido en arte "explotando una doble poética de la imagen al convertir sus imágenes, simultáneamente o por separado, en dos cosas: en los testimonios legibles de una historia escrita en los rostros o los objetos y de bloques puros de visibilidad, impermeables a toda narrativización y a todo pasaje del sentido". Una imagen estética que pueda ser a la vez cifra de la historia e interrupción (del flujo mediático).

trazado, lo real y lo imaginario, el objeto por fotografiar y el sujeto que fotografía, la técnica y el arte, el sin-arte y el arte, etc. En todas estas duplas, lo más importante, lo más fotográfico y lo más rico en potencialidades artísticas, es justamente el "y", fundamento mismo de estas duplas; es decir el "a la vez" ya visto por Aristóteles." (Soulages, 2008, p. 103) 
Por otra parte, en términos lingüísticos, aunque unas pocas palabras logren leerse en las imágenes (como por ejemplo la palabra "chorros", es decir, "ladrones" en la jerga lunfarda porteña), la lectura se dificulta y ni bien se la deja de leer, cada palabra vuelve a participar del reino de las formas y el color. Sin ahondar en explicaciones, Travnik le escapa también a registrar simplemente los grafitis o los carteles. Estas fotos revelan la escenografía de una ciudad en crisis, exponen la puesta escenográfica, casi de telón, de estos bancos. Se trata de una puesta que delata enseguida la violencia que pueden portar -la violencia que provocan- estas estructura de chapas.

La breve serie Bancos dialoga con la desolación y continúa la línea de los paisajes urbanos del libro Los restos (Travnik, 2007), que parecen expresar la afirmación de Soulages (2005, p. 136) acerca de que "la fotografía es la articulación entre la pérdida y el resto". Allí, en Los restos, Travnik recorre la ciudad durante las últimas décadas para advertir un presente repleto de restos del pasado a desentrañar. Las fotos de este libro parecen precisar un tiempo más largo de lectura: son fotos lentas, interesadas en la demora detallada de una forma, de un lugar, de un clima. Hacen que lo normal se vea extraño; obligan a detenerse a mirar, a escudriñar las luces, a encontrar los restos. Frente a una arquitectura, a Travnik le interesa ir más allá del registro para encontrar "el escenario, el drama, la acción, esa cosa urbana que está en nuestras vidas. Me interesa el hecho de conseguir una buena imagen, si hay una sombra, un rastro, algo que me permita contar una historia". (en Etchelecu, 2016) Sus fotos recorren la ciudad (las ciudades, es decir, toda ciudad) y muestran en blanco y negro sus diversos espacios vacíos de presencia humana. Retratan anodinas escenas del paisaje urbano y, al hacerlo, crean climas y situaciones ambiguas y misteriosas: una casa con puerta y ventanas de cortina metálica cerradas aunque sin paredes detrás, árboles reales confundidos con dibujos de árboles, construcciones cerradas y puertas tapiadas, vegetales trepando a carteles o apareciendo apenas en medio del hormigón de las casas. Naturalezas muertas de la ciudad, postales que parecen las 'vistas' de los viajeros de antaño pero desesperanzadas. Arquitecturas sin gente: sitios ensombrecidos y extraños, climas enrarecidos. 
En el texto que acompaña las imágenes del libro Paisajes (Travnik, 2014), Julio Fuks subraya la importancia que tienen los paisajes (en su mayoría urbanos) a lo largo de su obra.

El paisaje y el retrato son sus áreas de trabajo más destacadas. En tanto paisaje, al componerlos, demora su mirada en fragmentos de zonas urbanizadas, o en sus extramuros. Imágenes que alternan de manera dialéctica entre naturaleza y cultura, entre lo familiar y lo no visto, entre formas que se acoplan a partir de sus diferencias o de su continuidad. Elabora su poética con elementos mínimos de lo real y la reinventa cuando [luego del formato cuadrado] incorpora a su obra el formato apaisado a las vistas. (Fuks, 2014)

Retomando, hay entonces en cada una de estas fotos de Bancos una aparición muy sutil de las marcas o, para continuar con el vocabulario de su obra, de los restos de la protesta allí en la pintura, en las capas superpuestas de sucesivas manifestaciones y borramientos, en el pegar y despegar carteles, en el nunca despegar del todo la goma con que los papeles se adhirieron a la chapa. Las fotos dicen mucho más que un registro documental o de relevamiento, y a la vez no dejan de hablar de ello ni de registrarlo: dan cuenta de estos palimpsestos (en términos de Dubois, 1986). La superposición de capas de sentido, ocultas a la vez por su misma ilegibilidad y su quebrada visibilidad, adquieren entidad en estas fotos de Travnik. 9

Por otra parte, justamente el tema de cada imagen se escabulle y se presenta a la vez en todo momento, la dialéctica entre lo visible y lo no mostrado, así como entre lo sensible y lo que se sabe, va configurando así una interesante clave de lectura del pasado reciente en estas memorias fotográficas de la crisis. En las obras de Travnik aparece la historia como resto, tensionando la superficie fotográfica, a la vez documental y abstracta. La historia -en particular los sucesos alrededor del corralito bancario y las protestas durante la crisis- deja sus huellas en la superficie de la imagen para que el espectador desande estos indicios.

9. Travnik ha precisamente afirmado que la fotografía tiene un "elevado contenido simbólico y poético. (...) Las fotografías son, en la mayor parte de los casos, imágenes inasibles y con posibilidad de tener múltiples lecturas". (citado en Centro Cultural Haroldo Conti, 2012) 


\section{La superficie como trazo}

Nuna Mangiante es una artista argentina nacida en Córdoba. Se formó en la Escuela Provincial de Bellas Artes Dr. Figueroa Alcorta (Córdoba) y en la Escuela Nacional de Bellas Artes Prilidiano Pueyrredón (Buenos Aires). Dicta clases como profesora de arte y ha participado en numerosas muestras nacionales e internacionales. Su obra, producida a partir de los años 90, gira principalmente alrededor del dibujo con lápiz en diversas superficies, incluyendo fotografías.

En su libro Corralito (2009) ${ }^{10}$, Mangiante presenta a partir de fotografías los escenarios de las fachadas de las entidades bancarias porteñas. En rigor, capturó los parapetos de sus flamantes segundas fachadas (de chapas y hierros) que ella misma narra haber golpeado junto a desconocidos, otros ahorristas. Y a estas capturas hechas en 2001-2002 luego las intervino a mano con grafito para asemejar la imagen a su experiencia y para crear, en palabras de la artista, su "propia representación de lo vivido por la violencia del sistema".11

Mangiante instala su experiencia vivida como central al reconstruir la génesis de esta serie:

Violencia social, la sentí, mientras iba caminando al microcentro, igual que muchos y ime di cuenta que mi piel era igual a la de las gallinas! porque yo era los otros. Habíamos sido desplazados de nuestra cotideaneidad a la fuerza, y en el desplazamiento yo era gentes (nada peor, ya que conmigo misma, me

\footnotetext{
10. La primera exhibición de algunas las fotos de estas serie también fue en 2009, en la Galería Zabaleta Lab, acompañadas por un texto del artista argentino León Ferrari.

11. Salvo que se diga lo contrario, todos los testimonios de Mangiante provienen de comunicaciones por mail mantenidas con ella durante septiembre de 2017. Allí ha afirmado haber realizado en dos tramos el proceso de esta serie: "Del 2001 al 2002 fue que comencé con la idea y recorría el microcentro viendo todo el panorama y haciendo tomas como para documentar y ver cómo sería luego el trabajo. Sabía que era una situación histórica y que debía denunciar de alguna manera con una nueva serie de obras, pero no sabía cómo. Me acuerdo que me corrió la policía porque también hacía tomas de noche y no les gustó mucho jaja! Una vez que vi todo el material, comencé a decidir qué haría con la selección de las tomas definitivas: qué bancos, si debería haber personas o no, etc. Todo éste trabajo, te lo resumo, quedó guardado porque nadie quiso exponerlo. En el 2009, estando en el centro veo que había algunos sectores marcados todavía por los golpes de cuchillos y demás objetos en algunas zonas y tomé la decisión de retomar el proyecto que llamé Los Recuerdo del Corralito, de donde surgen las fotos de acercamientos más abstractos y de colores. Con el texto de León Ferrari me presento a la Galería Zabaleta Lab, en ese entonces en San Telmo, y gracias a León es que puedo hacer muestra allí."
} 
alcanza y sobra... ) pero era necesaria esa transformación, entonces asumí a mis otros y al mí propio para intentar voltear vallas, muros y cercos de acero, cobre y chapa.

Nos habían robado. (Mangiante, 2009, p. 43)

Cuando Mangiante habla de quienes tomaron las decisiones habla de "los abstractos del poder, los intangibles", de los humanos que deshumanizan. Los constructores de muros.

Decía que salí con todos mis ajenos para tratar de solucionar algo de ese abuso y me encontré con estos monumentos fabricados por los intangibles cuyas entradas estaban tapiadas, valladas, con barreras. (...)

¿Qué significan estos muros y vallas? (Mangiante, 2009, p. 43)

Así, en primer lugar esta obra se proponen anudar simbólicamente, es decir, transmitir, una experiencia concreta de la artista. La experiencia de encontrarse, allí en la puerta de los bancos, con otras personas formando parte de un anónimo y espontáneo grupo que acuerda tácitamente realizar cierta práctica de protesta -como una orquesta sin director, parafraseando a Bourdieu (2008) cuando describe la lógica de la práctica-.

Otra cuestión que remarcan sus narraciones acerca del origen de estas obras se ligan a una característica de los acontecimientos de diciembre de 2001 y los meses posteriores: la experiencia que vive y narra visualmente la artista es colectiva. Ella deja entrever, en su relato, este fundirse en otros, en gentes (no es casual este vocablo, ligado a la clase media que fue sujeto principal de las protestas frente a los bancos ${ }^{12}$ ). A este respecto, en uno de los textos del libro que acompaña a estas obras, Lucas Rubinich delinea la particularidad del 2001. "Obviamente no se trataba de 'El Cordobazo'. Era la rebelión de los individuos a los que el sistema de dominación, que habían legitimado y que les había hecho compartir cierta efervescencia producida por la llegada de mundos nuevos, había traicionado". (Rubinich, 2009, p. 9) El autor también

12. Una de las prácticas de protesta de la clase media fue conocida como Cacerolazo, cuyas marchas se hacían al son de los golpes de cacerola y bajo el lema "iQué se vayan todos!". Incluso, uno de sus cantos se solidarizaba -al menos momentáneamente- con los reclamos y medidas de protesta de los sectores populares más vulnerados, al entonar: "Piquete y cacerola, la lucha es una sola". Para el tema de las identidades de la protesta y la relación entre piqueteros y caceroleros, véase Barbetta y Bidaseca (2004). 
distingue otra particularidad: se trata de muchedumbres rebeladas -no de colectivos reales- pero que igualmente tienen aspectos transformadores de las visiones del mundo. Siguiendo esto, es interesante pensar la distancia entre un colectivo político y esta suerte de fusión con ajenos y otros.

Mangiante se hace una pregunta: "¿qué significan estos muros y vallas?". Como se argumentó más arriba, es la propia arquitectura de las instituciones bancarias la que inscribe en el entramado urbano la centralidad de su poder. Las nuevas adendas fortificadas de sus edificaciones violentan aún más la relación desigual con el entorno. Rubinich sostiene que los bancos, símbolo del sistema de relaciones económicas, despliegan estas "vallas de metal que las protegen de estos nuevos atacantes que son ciudadanos convencionales, habitualmente respetuosos de la ley, clientes depositantes, bases sociales activas de ese sistema de dominación". (Rubinich, 2009, p. 11-12) Estos anónimos ahorristas devenidos atacantes forman la agrupación espontánea de la que participó la artista durante las protestas. Así, esta obra se funda desde su origen como un testimonio, que es colectivo antes que individual, y una pregunta. Mangiante narra cómo golpea con fuerza, y con más fuerza todavía estas chapas, hundiéndolas y dejando su marca. En su libro, junto a los textos y antes de llegar al corazón del conjunto visual, intercala imágenes de estas huellas, como un preparado visual para la verdadera serie fotográfica que documente transformadamente estos hechos: la imagen intervenida.

Luego de esa experiencia de golpear y marcas vallas, Mangiante (2009, p. 45) encuentra una idea para "transportar en imágenes la potencia de las experiencias vividas". Entonces utiliza la cámara fotográfica para registrar estos monumentos bancarios. Toma imágenes sin personas, vaciadas de gente, diurnas, a color. No se trata de fotos oscuras (o pictóricas, como las que Travnik ha tomado de las mismas construcciones, o incluso como las fotos más coloridas y de planos cortos que también forman parte del libro de Mangiante). En estas imágenes, los bancos están tomados de frente, sus fachadas en tonos apagados llenan cada foto, en la que se recortan a veces objetos más coloridos como la bandera de Argentina, el logo del banco o 
alguna línea de color propia de la imagen empresarial que irrumpe sobre las paredes exteriores.

Cualquiera que haya atravesado el microcentro porteño encontrará a estas fotos corrientes, paisajes ya vistos y registrados con exactitud. Sin embargo, a Mangiante las fotografías se le revelaron fallidas. Los edificios, las vallas. las chapas: en las fotos, nada de esto tenía el clima que ella había vivido, no la conmovían ni la remitían a "la violencia social que habíamos padecido" (Mangiante, 2009, p. 45). El registro fotográfico aparecía como fallo y la foto no le resultaba suficientemente mimética. $\mathrm{O}$, más bien, era en su realismo donde justamente perdía aquello que transmitía, algo de la experiencia que resultaba intransmisible por vía de estas imágenes fotográficas: aquellos monstruos de chapas y acero ya no lo eran tanto, parecían corrientes, más pequeños.

Así que hizo algo con ellos: los tapó.

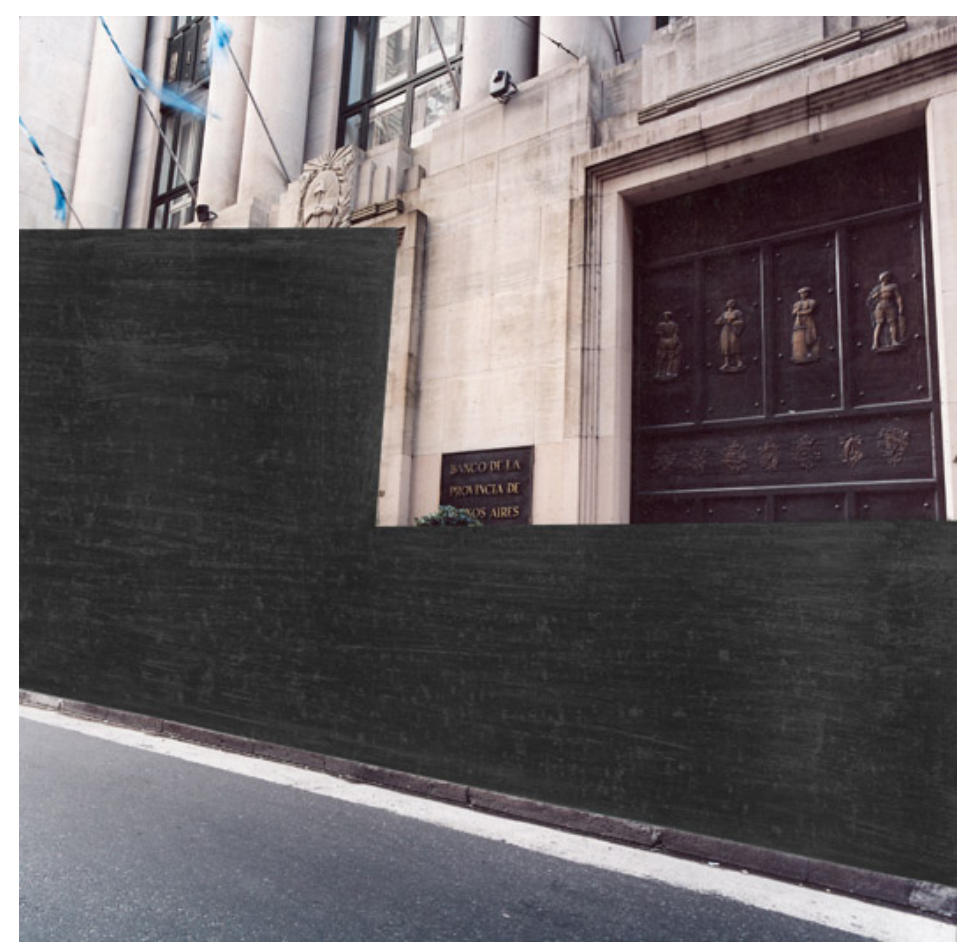

F5. Nuna Mangiante, "Banco de la Provincia de Buenos Aires”.Grafito sobre fotografía. Negativo 6x6. Proceso Digital . 100 x 100 cm. 2001 


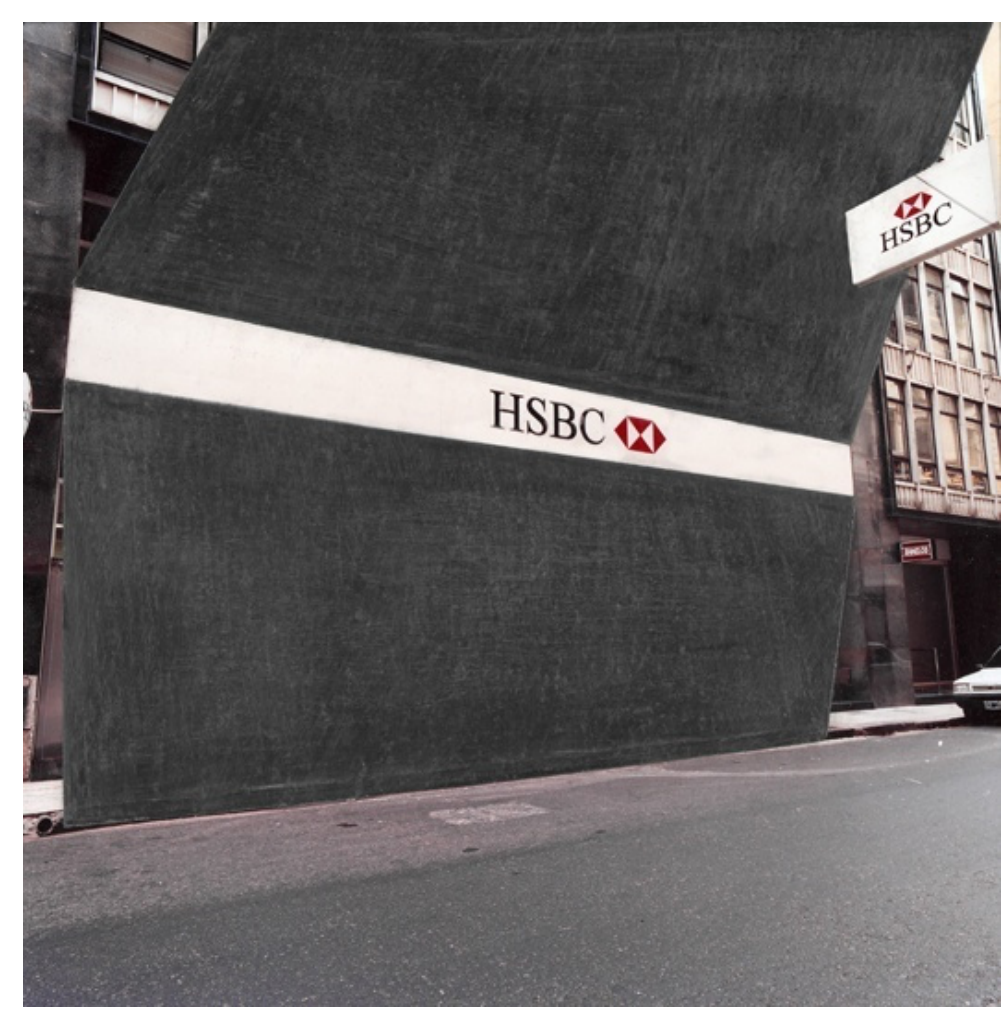

F6. Nuna Mangiante, “CBSH”. Grafito sobre fotografía. Negativo 6x6. Proceso Digital . 100 x $100 \mathrm{~cm} .2001$

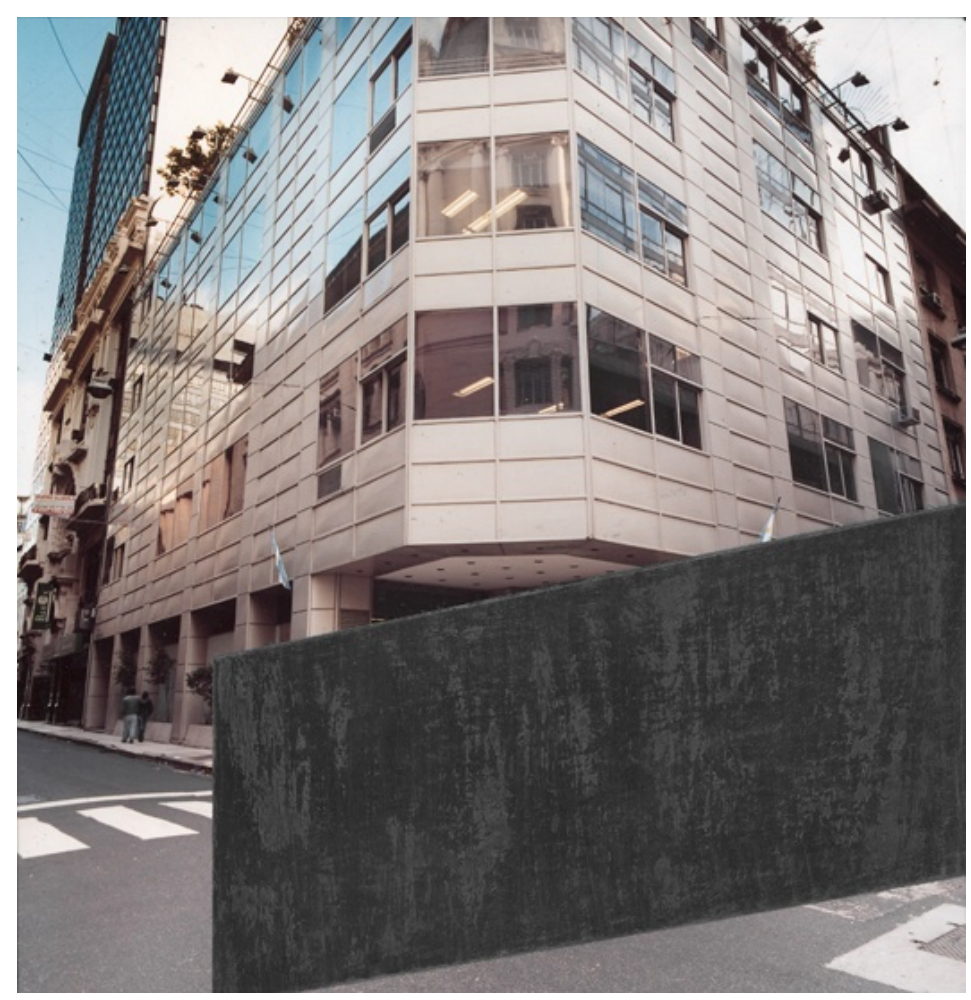

F7. Nuna Mangiante, "Vamos Ricardo Serra todavía!". Grafito sobre fotografía. Negativo 6x6. Proceso Digital . 100 x 100 cm. 2001 


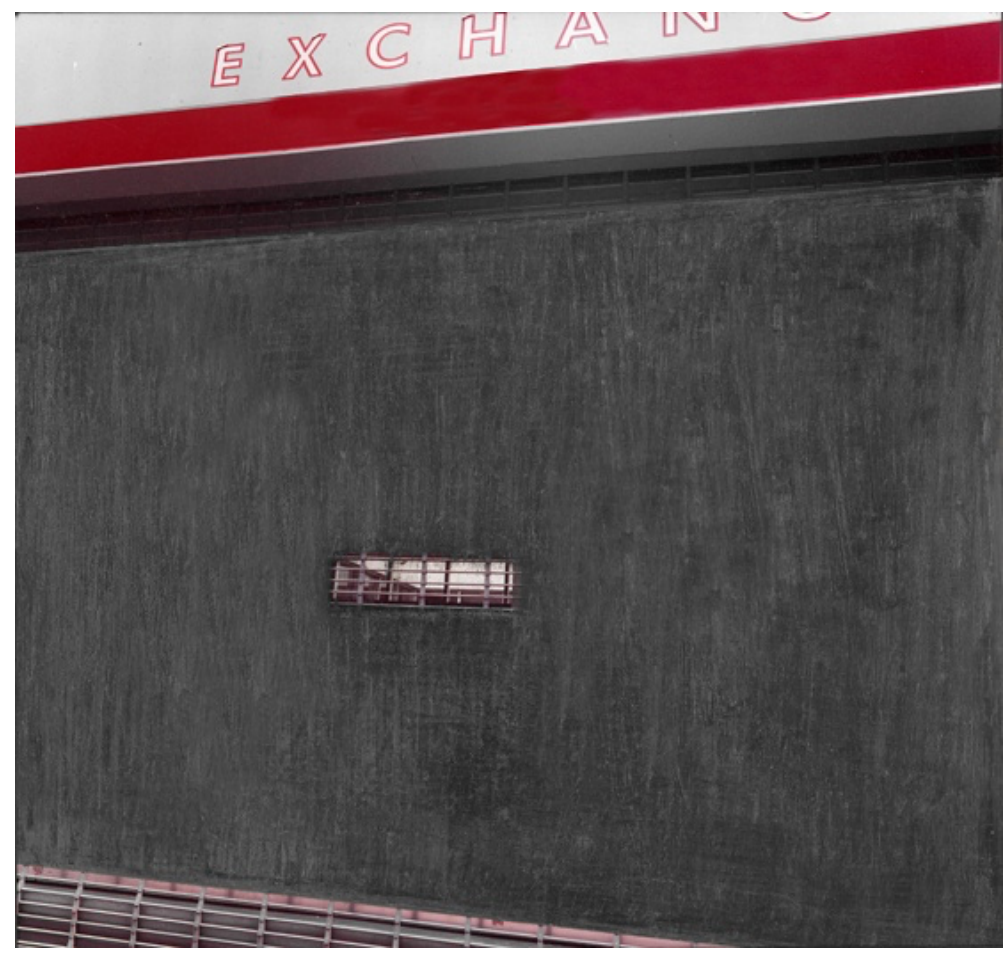

F8. Nuna Mangiante, "Se atiende por la Mirilla”. Grafito sobre fotografía. Negativo 6x6. Proceso Digital . 100 x $100 \mathrm{~cm} .2001$

Habiendo ya usado el grafito como material constitutivo de su obra, Mangiante cubrió grandes áreas de las fotos con formas geométricas. En especial, dibujó sobre los vallados de los bancos e incluso los agrandó y continuó, porque en las fotos no le resultaban suficientemente altos. En sus palabras, los exageró y sacó "de los planos lógicos de la visión" creando su "propia representación de lo vivido por la violencia del sistema" (Mangiante, 2009, p. 45). Y este excedente, esta intervención posterior, tenía un patrón o incluso una figuración previa a la toma de la fotografía. Según sus palabras, "las fotos están cuidadosamente estudiadas, ángulos, proporciones, luz y sobre todo, cómo serían las intervenciones futuras". ${ }^{13}$

Este recurso del grafito sobre chapa (fotografiada), estas intervenciones a mano complejizan cada foto en múltiples dimensiones.

13. Este plan previo a la imagen se advierte también en la manera en que Mangiante es muy celosa de la calidad fotográfica de su trabajo: "Las fotos del 2001-2002 fueron sacadas con una cámara Hasselblad analógica de formato 6x6 y luego desarrollé el proceso digital. Yo necesitaba que las tomas fueran con una cámara de esta categoría, por el tema de los lentes. Yo no tenía cámara en ese entonces así que trabajé con G. Lowry, una de las personas que más sabe de fotografía en el medio". 
Por un lado, lo tachado tapa aquello que es justamente la particularidad arquitectónica de la crisis bancaria y el corralito. Los vallados, protagonistas de este libro, son aquello -lo único- que no se muestra. Y que sin embargo aparece más monstruoso que nunca, en una extraña metamorfosis, mutando de forma y de materia. El trazo tacha y muestra. Sobre el material con el que Mangiante compone estas obras, Lux Lindner (2014) afirma que "en los dibujos grafitados el punctum está en la relación entre el grafito y la luz. El grafito, material que tanto se usa en lápices y computadoras, despliega toda su propiedad física de lustre al ser poseído por esas vibraciones electromagnéticas que conocemos como... luz". Liso, gris y luminoso, el grafito además borra lo marcado, justamente la huella humana de la protesta (las abolladuras, las marcas en la chapa). Y borra estas huellas mediante la incorporación de otro trazo: el de la mano de la artista, que tanto antes ha golpeado como ahora dibuja estos mamotetros parcos. ${ }^{14}$

¿Qué borra y qué subraya, a la vez, el trazo de grafito? ¿Por qué el grafito viene a suplir aquella violencia que las fotos no parecían capaces de transmitir? ¿Será esta opacidad, como sostiene Danielle Perret (2009, p. 32), también una violencia cometida a la representación misma?15

Tal como hacía, según Batchen, el pincel que pintaba la fotografía, las intervenciones con grafito de Mangiante subrayan el carácter material de lo fotográfico y nos instan a pensar en su superficie como pintable, intervenible. Por el pulso mismo del dibujo y por su grado de abstracción, las intervenciones son evidentes: se destacan e insertan en la superficie fotográfica como un apéndice. Los insertos grises no se plantean como una segunda capa natural sino como aquello que violenta geométricamente aquello que se muestra/no muestra. La sublevación visual -además de dar vida a un nuevo e impostado parapeto- es aquí correlato de la sublevación

\footnotetext{
14. El artista León Ferrari, en el epígrafe del libro de Mangiante, se refiere a la "originalísima parquedad negro + blanco + foto + grafito" de esta obra.

15. Estas imágenes en crisis pueden relacionarse incluso con la crisis de representación de los partidos políticos de la cual en parte son expresión los sucesos de diciembre de 2001. Ya que el estallido de diciembre se desarrolló "desde la oposición a políticas de gobierno hasta la oposición al gobierno mismo, y, finalmente, al conjunto del sistema institucional político incluyendo a los beneficiarios e impulsores de las políticas aplicadas desde 1976". (Iñigo Carrera y Cotarelo, 2006, p. 88)
} 
física de los ahorristas contra las chapas. Es un gesto de violencia contra lo fotográfico: tacha la foto como el martillo hiende la chapa. Una sublevación o intervención que, por otra parte, no deja de ser controlada, con límites precisos. De hecho, Mangiante usa "barras de grafito rectangulares 6B ya que lápiz marcaría el papel fotográfico, es muy delicado". Prolijas, estas réplicas de vallas, igual que sus hermanas originales, impiden el paso y la vista: no pueden atravesarse y todo en ellas resulta un símbolo de esta prohibición (son eficaces como advertencia y amenaza). Las vallas segundas, las grises de grafito, dotan además a los edificios de una virtualidad, les quitan el asidero urbano, los deslocalizan. En este punto se relaciona también con la abstracción documental de las fotos de Travnik, en este caso insertando en el horizonte urbano -más precisamente, bancario- una geometría extraña. Se hace necesario ver las otras fotos de la serie (las huellas de los martillos en las chapas) y los paratextos (títulos, textos de Mangiante y otras personas) para entender que estas imágenes no podrían referir a ningún otro lugar. Una combinación entre implicación y explicación que, en términos de Didi Huberman (2008), carga de sentidos a las obras y vuelve a estas fotografías claras evocaciones de la crisis de 2001 y su poscrisis.

\section{Conclusiones: desplazamientos y transformaciones}

La fachada de un edificio es su cara, su rostro, la mostración pública y exterior de su interior. Es aquello de cada construcción que la pone en relación con otras y la inserta en lo urbano, es su superficie así como la piel es el órgano de los cuerpos que nos relaciona con el mundo social -la piel también es interior/exterior, como la mayoría de las fachadas-. Esta relevancia de la fachada es aún mayor en las imponentes edificaciones de los bancos de la ciudad de Buenos Aires.

Son estas propias fachadas de las entidades bancarias las que se cubrieron durante el corralito, anuladas con vallas y obstáculos para sustraerse del afuera. Sobre esta intervención primera -sobre estos obstáculos- se montan los artefactos de las dos series fotográficas trabajadas. 
En el caso de Travnik, la fotografía aparece como una superficie que retrata superficies, casi ocultándose como fotografía, haciéndose abstracta a la vez que revelándose como documento. Este acercamiento al objeto retratado que hace Travnik es un acercamiento a color y de superficie. Sus fotografías contienen el estallido de la crisis en forma de resto y conforman un desplazamiento. La abstracción documental se despliega aquí en tanto operación de la propia fotografía, que ofrece unas huellas pictóricas de aquello a lo que solamente alude.

Mangiante, al tachar, tapar y agigantar estas construcciones ad hoc de los bancos, trabaja la superficie fotográfica -así como antes intervenía con sus golpes la superficie de las fachadas bancarias en el microcentro junto a otros. En la tensión entre lo que se muestra y lo que se tacha radica el nudo de esta serie, en la transformación de aquella violencia contra las chapas en la tachadura del grafito que hiende las fotografías. Es en la superficie material de lo fotográfico que Mangiante inscribe sus geométricas formas de grafito. Inscribe en la imagen la violencia material del agregado a lápiz que tacha, a la vez que subraya lo que oculta: los parapetos bancarios. Cuando ella sostiene que, durante las protestas del corralito, fue desplazada de su cotidianeidad a la fuerza, este desplazamiento que la transforma en otra cosa (en "gentes") se replica en lo que hacen sus dibujos en cada imagen.

Desplazamientos y transformaciones tensan las superficies de lo fotográfico en estas series, al trabajar con lo documental y volverlo un objeto extraño y en crisis. En esta línea, estos artistas -ambos desde operaciones sobre la superficie-, revisan fragmentos urbanos familiares y reconocibles y los invisten de extrañeza. Travnik despliega una poética del resto a partir de sus abstracciones documentales y Mangiante interviene la materialidad de superficie, tachando para desocultar. Ambos articulan una porción específica del paisaje urbano de la poscrisis, esa particular corteza de la historia, para tensionar la representación y volverse artefactos y dispositivos visuales memorias fotográficas- que evocan y traccionan el pasado reciente. 


\section{Referencias bibliográficas}

Barbetta, P. y K. Bidaseca (2004). Reflexiones sobre el 19 y 20 de diciembre de 2001. 'Piquete y cacerola, la lucha es una sola': ¿emergencia discursiva o nueva subjetividad? Revista Argentina de Sociología 2 (002). En línea en https://www.redalyc.org/pdf/269/26920205.pdf

Batchen, G. (2004). Forget me not. Photography \& Remembrance. Nueva York: Princeton Architechtural Press.

Bourdieu, P. (2008). El sentido práctico. México: Siglo XXI.

Didi-Huberman, G. (2008). La emoción no dice yo. En Didi-Huberman, Pollock, Rancière, Schweizer y Valdés (comp). Alfredo Jaar. La política de las imágenes. Santiago de Chile: Metales Pesados.

Didi-Huberman, G. (2014). Cortezas. Santander: Shangrila.

Dubois, P. (1986). El acto fotográfico. De la Representación a la Recepción. Barcelona: Paidós.

Centro Cultural Haroldo Conti (2012). Entrevista a Juan Travnik. Abril, Buenos Aires. En línea en http://conti.derhuman.jus.gov.ar/2012/04/noticias-entrevista-ajuan-travnik.shtml

Etchelecu, L. (2016). Juan Travnik. Fotógrafo, gestor cultural, curador. El gran otro del 27 de octubre. En línea en http://elgranotro.com/juantravnik-fotografo-gestor-cultural-curador/

Edwards, E. y J. Hart (2004). Photographs Objects Histories. On the Materiality of Images. Nueva York: Routledge.

Flusser, V. (2015). El universo de las imágenes técnicas. Elogio de la superficialidad. Buenos Aires: Caja negra.

Fortuny, N. (2014). Memorias fotográficas. Imagen y dictadura en la fotografía argentina contemporánea. La Luminosa: Buenos Aires. Disponible también en https://issuu.com/espacioeclectico/docs/libro_natalia fortuny

Fortuny, N. (2017). Leer el tiempo: memorias fotográficas de la crisis argentina de 2001. Photo \& Documento Nro 4 - Diciembre 2017, Brasilia.

http://gpaf.info/photoarch/index.php?journal=phd\&page=article\&op $=$ view\&path $\% 5 \mathrm{~B} \% 5 \mathrm{D}=172$

Fortuny, N. (2018). Signo de (nuestro) tiempo. Fotografía, historia y dispositivos visuales a partir de la obra de Gabriel Valansi. En E. Rosauro y J. Solano (Eds.), Lámparas de mil bujías. Fotografía y arte en América Latina desde 1839 (pp. 346-371). Editorial Foc: México.

Fuks, J. (2014). El resplandor próximo. En J. Travnik. Paisajes. Nueva York: Antennae. Disponible también en línea: http://experimenta.biz/revistaexperimenta/15903-2/ 
Giunta, A. (2009). Poscrisis. Arte argentino después de 2001. Buenos Aires: Siglo XXI Editores.

Iñigo Carrera, N. y M. C. Cotarelo (2006). Génesis y desarrollo de la insurrección espontánea de diciembre de 2001 en Argentina. En G. Caetano (coord.), Sujetos sociales y nuevas formas de protesta en la historia reciente de América Latina. CLACSO, Grupos de Trabajo. En línea en http://bibliotecavirtual.clacso.org.ar/ar/libros/grupos/caeta/PICdos. pdf

Liernur, J. y F. Aliata (2004). Diccionario de arquitectura en la Argentina: estilos, obras, biografías, instituciones, ciudades. Buenos Aires: AGEA.

Lindner, L. (2014). Texto curatorial de la muestra Contemporáneo 31. Lo contrario de la magia, del 28.03.2014 al 27.07.2014. Buenos Aires: MALBA.

Longoni, A. (2004). Museo o revuelta, Revista Lezama $N^{o}$ 6, Buenos Aires, septiembre $32-37$.

Longoni, A. (2007). Encrucijadas del arte activista en Argentina. Revista Ramona $n^{0}$ 74, septiembre, 31-43.

Longoni, A. (2009). Activismo artístico en la última década en Argentina: algunas acciones en torno a la segunda desaparición de Jorge Julio López, e Introducción al Dossier "Arte y Activismo". En Revista de Artes Visuales Errata ${ }^{\circ} O$, Bogotá, Diciembre de 2009.

Mangiante, N. (2009). Corralito. Buenos Aires: Patricia Rizzo Editora.

Perret, D. (2009). El futuro de la memoria. En Mangiante, N., Corralito. Buenos Aires: Patricia Rizzo Editora.

Rancière, J. (2011). El destino de las imágenes. Buenos Aires: Prometeo.

Rubinich, L. (2009). No confundir 'gordura' con 'hinchazón'. En Mangiante, N., Corralito. Buenos Aires: Patricia Rizzo Editora.

Soulages, F. (2005). Estética de la fotografía. Buenos Aires: La marca.

Soulages, F. (2008). Para una nueva filosofía de la imagen. Revista de Filosofía y Teoría Política, (39). Disponible en: http://www.fuentesmemoria.fahce.unlp.edu.ar/art_revistas/pr.3625/ pr.3625.pdf

Travnik, J. (2007). Los restos. Buenos Aires: Dilan Editores.

Travnik, J. (2014). Paisajes. Nueva York: Antennae.

Vázquez, C. (2011). Prácticas artísticas de protesta y política en la Ciudad de Buenos Aires (2003-2007). Tesis Doctoral. Facultad de Ciencias Sociales, Universidad de Buenos Aires, mimeo.

Zicari, J. (2014). El réquiem del uno a uno. Tres corridas bancarias y la instauración del corralito en el final de la convertibilidad, Realidad Económica, Buenos Aires, 33-65. 